\title{
O acordo de não persecução penal e o paradigma da prevenção no enfrentamento à corrupção e à macrocriminalidade econômica no Brasil: novas alternativas ao modelo punitivista tradicional
}

Non-prosecution agreement and the paradigm of prevention in the fight against corruption and economic macrocriminality in Brazil: new alternatives to the traditional punitive model

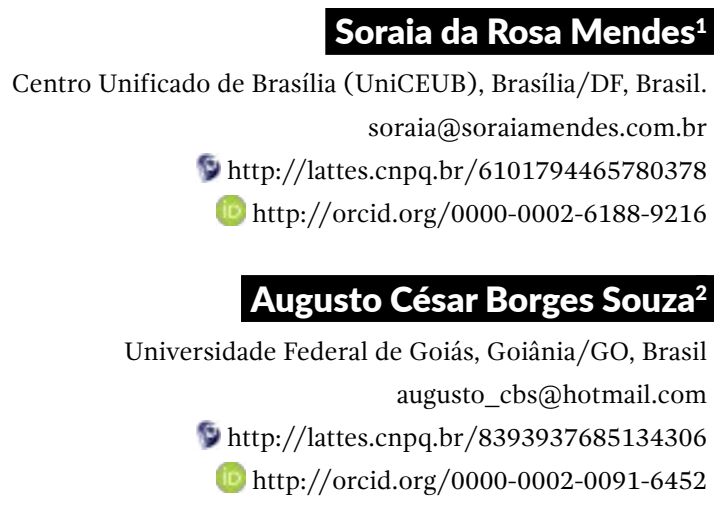

Resumo: O presente artigo pretende analisar as recentes alterações legislativas ocorridas no Brasil, em especial a instituição de meca-

1 Pós-Doutora em Teorias Jurídicas Contemporâneas Universidade Federal do Rio de Janeiro, UFRJ. Doutora em Direito, Estado e Constituição pela Universidade de Brasília, UnB. Mestra em Ciência Política pela Universidade Federal do Rio Grande do Sul, UFRGS. Professora Associada do PPG Mestrado e Doutorado em Direito do Centro Unificado de Brasília - UniCeub. Professora da Faculdade de Direito da Universidade Presbiteriana Mackenzie. Advogada sócia-diretora do Soraia Mendes, Marcus Santiago \& Advogadas Associadas.

2 Mestrando do Programa de Pós-Graduação em Direito e Políticas Públicas da Universidade Federal de Goiás (PPGDP-UFG). Pós-graduado em Direito Público pela Faculdade Baiana de Direito. Graduado em Direito pela Universidade Federal da Bahia (UFBA). Promotor de Justiça do Ministério Público do Estado de Goiás. 
nismos consensuais de solução de conflitos e seus impactos no enfrentamento à corrupção e à macrocriminalidade econômica. Utilizando como referencial teórico a ideia de prevenção técnica, propugnada por Winfried Hassemer, pretende-se avaliar se a justiça penal negociada representa efetiva alternativa ao paradigma punitivista dominante, possuindo maior aptidão para reduzir a impunidade e aumentar as cotas de prevenção de ilícitos contra a Administração Pública e a ordem econômica. Inicialmente, serão abordados alguns aspectos criminológicos dos delitos de colarinho branco, bem como fatores de ordem político-criminal que colocam o ideal de prevenção como vetor central do sistema de justiça criminal contemporâneo. Em seguida, será analisada a insuficiência do modelo tradicional de persecução penal brasileiro, fundado na litigiosidade, e sua ineficiência para lidar com os casos relacionados à macrocriminalidade econômica e à corrupção. Finalmente, serão analisados os principais aspectos atrelados à implementação de novos mecanismos consensuais de solução de conflitos na seara penal, os prognósticos de cunho político-criminal no tratamento da corrupção e da criminalidade organizada e seus impactos na atuação do Ministério Público e do Poder Judiciário.

Palavras-chave: Corrupção; Macrocriminalidade; Justiça penal negociada; Prevenção técnica.

ABSTRACT: This article intends to analyze the recent legislative changes that have occurred in Brazil, especially the establishment of consensual forms of dispute resolution and their impacts in the fight against corruption and economic macro-criminality. Using the idea of technical prevention as proposed by Winfried Hassemer as a theoretical framework, it is intended to assess whether negotiated criminal justice represents an effective alternative to the dominant punitivist paradigm, with greater ability to reduce impunity and increase crime prevention indexes related to offenses against Public Administration and the economic order. Initially, some criminological aspects of corruption and macroeconomic criminality will be addressed, as well as political-criminal factors, which place the ideal of prevention as the central vector of the contemporary criminal justice system. Then, the insufficiency of the traditional model of Brazilian criminal prosecution, based on litigation, and its inefficiency in dealing with cases related to economic macro-crime and corruption will be analyzed. Finally, the main aspects related to the implementation of new consensual forms of dispute resolution in the criminal field, the political-criminal prognoses in the 
treatment of corruption and organized crime and their impacts on the performance of prosecution and judicial branch.

KeYwords: Corruption; Macro-criminality; Negotiated criminal justice; Technical prevention.

SUMÁRIO: Introdução; 1. A "criminalidade do colarinho branco" e o paradigma da prevenção; 2. A persecução penal da corrupção no Brasil e a insuficiência do modelo atual de gestão de conflitos; 3. A consensualidade como estratégia político-criminal no enfrentamento à corrupção e à macrocriminalidade econômica; Considerações finais; Referências.

\section{INTRODUÇão}

Como é consabido, o modelo tradicional de persecução penal não vem se revelando suficiente para que o enfrentamento à macrocriminalidade econômica e à corrupção seja exercido de maneira ideal no Brasil. Primeiro, porque tal modelo prioriza o aspecto repressivo, revelandose pouco ou nada eficiente na prevenção de fraudes e danos ao erário. Segundo, porque o próprio sistema de justiça não se mostra efetivo na responsabilização dos agentes comprovadamente envolvidos em atos de corrupção, causando uma indesejável sensação de impunidade.

Com o escopo de aprimorar os mecanismos formais de controle e atendendo a compromissos firmados perante organismos internacionais, o Brasil vem incorporando novos instrumentos de prevenção e combate à corrupção. A Lei n ${ }^{\circ} 12.846$, de $1^{\circ}$ de agosto de 2013 (Lei Anticorrupção), por exemplo, constitui um marco para a chamada "autorregulação regulada” em matéria de corrupção, ao possibilitar a realização de acordos de leniência e estimular a instituição de mecanismos e procedimentos internos de integridade.

No mesmo sentido, a recém promulgada Lei $\mathrm{n}^{\circ} 13.964$, de 24 de dezembro de 2019 ("Pacote Anticrime"), promoveu inúmeras alterações visando aperfeiçoar o sistema processual brasileiro, dentre as quais se destaca a previsão de celebração de acordos de não persecução penal 
(ANPP) e cível (ANPC), aproximando o Brasil do modelo de justiça norte-americano e anglo-saxão.

Considerando o atual cenário legislativo e jurisdicional brasileiro, torna-se oportuno o presente estudo, o qual possui como problema de pesquisa o seguinte questionamento: a adoção de mecanismos de solução consensual de conflitos, introduzidos recentemente no ordenamento jurídico pátrio, possui maior aptidão para reduzir a impunidade e assegurar com mais efetividade a prevenção de ilícitos contra a Administração Pública e a ordem econômica do que o sistema tradicional de persecução penal, fundado na contenciosidade e na imposição de sanções por meio de sentenças condenatórias?

A dogmática penal contemporânea já reconhece a superação do paradigma punitivista no tratamento dos delitos de corrupção (compreendidos como espécie de criminalidade macroeconômica), exigindo, cada vez mais, a adoção de medidas que possuam caráter eminentemente preventivo, e não apenas simbólico. Nesse contexto, adota-se neste artigo, como referencial teórico, a ideia de prevenção técnica ou organizacional propugnada por Winfried Hassemer.

Valendo-se do método hipotético-dedutivo, o presente artigo parte da hipótese provisória segundo a qual a celebração de acordos de não persecução cível e penal representa efetiva alternativa ao sistema tradicional de justiça contenciosa no enfrentamento à corrupção e à macrocriminalidade econômica, possuindo maior aptidão para interromper processos delitivos e prevenir concretamente a ocorrência de novas infrações.

Pretendendo apresentar as causas e possíveis soluções ao problema investigado, este estudo possui viés explicativo, promovendo uma abordagem quantitativa-qualitativa do objeto de pesquisa, mediante apresentação de dados estatísticos e revisão bibliográfica.

Para tanto, serão feitos alguns apontamentos teóricos que colocam o ideal de prevenção como paradigma reinante no Direito Penal contemporâneo em matéria de macrocriminalidade econômica, identificando, a partir da concepção de prevenção técnica ou organizacional propugnada por Winfried Hassemer, a imposição de medidas de cunho preventivo e restaurador como política pública capaz de oferecer uma resposta adequada ao fenômeno da corrupção. 
Na sequência será abordada a insuficiência do modelo tradicional de persecução penal e cível brasileiro, fundado na litigiosidade, e sua ineficiência para lidar com os casos relacionados à macrocriminalidade econômica e à corrupção, identificando a impunidade e a impermeabilidade de tais tipos de ilícito frente às instâncias formais de controle.

Em um terceiro tópico serão analisados os principais aspectos relativos à implementação de mecanismos consensuais de solução de conflitos na seara penal e os prognósticos de cunho político-criminal no tratamento da corrupção e da criminalidade organizada, identificando de que forma as alterações legislativas deverão impactar na atuação do Ministério Público e do Poder Judiciário enquanto atores essenciais no processo de implementação de políticas públicas criminais em âmbito jurisdicional.

Por fim, serão apresentadas deduções e inferências relacionadas ao tema, assim como algumas considerações que, sem pretender esgotar o assunto, ao menos contribuam para enriquecer o debate sobre o problema e possam até mesmo fomentar a efetiva adoção de medidas de caráter preventivo e restaurador no tratamento do fenômeno corruptivo e da macrodelinquência econômica no Brasil.

\section{A "Criminalidade do colarinho branco" e o paradigma da PREVENÇÃO}

Desde que passaram a figurar como objeto de estudo das ciências criminais, a corrupção e a macrocriminalidade econômica, de modo geral, foram tratadas como fenômenos delitivos dotados de inegável equivalência epistemológica. Na verdade, observa-se que, atualmente, ambas as espécies criminológicas possuem causas semelhantes e apresentam-se como efeitos de uma mesma conjuntura histórica, o que também justifica o tratamento análogo conferido a tais modalidades delitivas tanto pela Criminologia quanto pela Dogmática Penal.

Ainda que a corrupção seja um fenômeno muito mais antigo (trata-se de conduta que remonta à Antiguidade, havendo registros de tipificação de tal comportamento desde o direito romano), é inegável que, na pós-modernidade, determinados fatores fizeram com que tanto 
ela quanto a macrodelinquência econômica fossem compreendidas como expressões de uma mesma realidade histórica e, por tal razão, fossem abordados de modo bastante semelhante pelas ciências criminais em geral.

Em que pese a sua antiguidade, a corrupção somente foi inserida como objeto de estudo da Criminologia no século XX, iniciando-se com os estudos da criminalidade do colarinho branco (white collar crime), termo cunhado por Edwin Sutherland, que, utilizando-se como critério de definição a qualidade do ofensor, adotou a expressão para caracterizar a criminalidade de postos mais elevados da sociedade, representando o conjunto de atividades ilícitas praticadas por indivíduos dotados de respeitabilidade e detentores de status social, no curso de sua atividade empresarial, que se diferencia qualitativamente do comportamento característico do restante dos criminosos (SUTHERLAND, 2016, 33-34).

Com o passar dos anos, passando-se o enfoque para a forma de atuação e objeto de seus atos, e não mais centrado na qualidade do autor, o termo passou a ser utilizado para designar a modalidade de crimes praticados no contexto empresarial e econômico, que não necessariamente tenham sido perpetrados por membros da elite (MACHADO; QUEZADO, 2018, p. 144).

Ainda que a aproximação entre os conceitos conduza a generalizações nem sempre adequadas, é possível afirmar que o estudo criminológico da corrupção e da macrocriminalidade econômica sempre esteve, de algum modo, correlacionado, assim como o tratamento conferido pela Dogmática Penal, razão pela qual ambas as modalidades serão tratadas no presente trabalho como fenômenos pertencentes a uma mesma categoria delitiva.

Conforme exposto, a criminalidade de colarinho branco somente ganhou a devida importância nos estudos criminológicos a partir da obra de Edwin Sutherland "White Collar Crime", publicada em 1949, como resultado de dezenove anos de pesquisa sobre práticas criminosas no âmbito empresarial. Adotando uma abordagem sociológica, Sutherland, ao explicar o comportamento delinquente como resultado das interações sociais do indivíduo e dos processos de comunicação oriundos do meio que o circunda, foi um dos grandes responsáveis por ampliar a crítica ao fenômeno criminal, até então explicado por padrões exclusivamente etiológicos. 
Segundo a teoria da associação diferencial, difundida por Sutherland, o comportamento criminoso não é determinado geneticamente, nem é produzido por problemas na personalidade nem da pobreza. Trata-se de um processo de aprendizagem proveniente da interação com outras pessoas no processo comunicativo, o que inclui não apenas as técnicas para o cometimento do delito, como também a racionalização do comportamento delinquente.

De acordo com Sutherland, a forma corporativa de organização empresarial possui a vantagem de uma maior racionalidade de suas ações. Uma racionalidade empresarial ressaltada em três aspectos: a) seleção de delitos que envolvem menor risco de descoberta e vítimas que estão menos propensas a contestar; b) escolha de crimes em que a produção de prova é mais difícil; c) adoção de "mecanismos de solução" (acordos de reparação). Com essa análise, o autor justifica a conclusão de que, em regra, os crimes praticados por empresas são deliberados e organizados (SUTHERLAND, 2016, p. 346-350).

Ao chamar a atenção para um tipo de criminalidade até então ignorado pelo sistema de justiça criminal e revelar o modo racional e organizado como os crimes de colarinho branco são praticados (o que inclui a sua capacidade de neutralizar as instâncias de controle), Sutherland ajudou a desnudar a desigualdade no sancionamento de certos agentes, contribuindo para atrair o foco dos estudos criminológicos para a delinquência empresarial e para denunciar a forma diferenciada como a justiça penal trata quem pratica essa espécie delitiva (SHECAIRA, 2018, p. 192).

Nos idos dos anos 60, a emergência da Criminologia Crítica, por sua vez, demonstrou a necessidade de promoção de uma política criminal destinada ao redirecionamento do poder punitivo para atingir setores historicamente alheios ao sistema penal:

Trata-se de dirigir os mecanismos da reação institucional para o confronto da criminalidade econômica, dos grandes desvios criminais dos órgãos e do corpo do Estado, da grande criminalidade organizada. Trata-se, ao mesmo tempo, de assegurar uma maior representação processual em favor dos interesses coletivos (BARATTA, 2011, p. 202). 
Nas décadas seguintes, vários estudos criminológicos acerca da criminalidade do colarinho branco sucederam-se, porém sem representarem grandes rupturas com as conclusões extraídas da teoria de Sutherland. Dentre elas, destaca-se a teoria da escolha racional (rational choice theory), desenvolvida na década de 1970 e que compreende o comportamento delitivo como fruto de uma escolha racional (perspectiva individual), na qual o sujeito avalia a relação de custo/benefício oriunda da prática criminosa, aferindo, racionalmente, as facilidades e dificuldades envolvidas no cometimento do crime (FERRAZ JUNIOR, 2017, p. 121). Tal teoria não trouxe grandes novidades em relação à teoria da associação criminal, que, algumas décadas antes, já assentava a ideia de que o indivíduo orienta-se pelo cometimento de um delito quando "(...) o peso das definições favoráveis excede o peso das definições desfavoráveis” (SUTHERLAND, 2016, p. 351).

Transpostas as bases da teoria da escolha racional para o estudo da corrupção, pode-se afirmar que:

Os homens que agem em nome da "racionalidade pública" o fazem sempre por meio de uma racionalidade individual referente a fins. Não importa se é por prestígio ou renda. O fato é que a lógica da ação é privada e não pública, individual e não coletiva. Como consequência imediata desse argumento aparece a possibilidade de combater a corrupção aumentando: a) os riscos inerentes à ação; b) os constrangimentos legais. Igualmente ao caso da licitação, o simples crescimento da complexidade legal não irá impedir a corrupção. Poderá até aumentá-la. Por outro lado, diminuir a sensação de impunidade aumentará o custo da ação corrupta e poderá ter um efeito devastador na corrupção. Nesse caso, a impunidade corresponde a um risco menor. (MAURO, 2003).

A grande contribuição dessa teoria, portanto, consiste no engajamento pela prevenção situacional do crime. De acordo com esse pensamento, o crime poderia ser melhor prevenido de duas grandes formas: por meio de mudanças na disposição do ambiente para reduzir as oportunidades que tornam o delito favorável ao infrator e pelo incremento dos riscos da atividade criminosa (FERRAZ JUNIOR, 2017, p. 122). 
Desse modo, foram edificadas duas grandes premissas que nortearam os estudos da corrupção e da macrocriminalidade econômica e influenciaram, inclusive, o tratamento de tais modalidades delituosas pela Dogmática Penal: a impermeabilidade dos crimes de colarinho branco frente às instâncias formais de controle (seletividade do sistema de justiça penal e cifras ocultas) e a necessidade de criação de estímulos dissuasivos, priorizando-se de uma abordagem essencialmente preventiva.

A tutela penal da moralidade administrativa, do patrimônio público, do meio ambiente e da ordem econômico-financeira sempre foi alvo de inúmeras críticas. Incumbiu à Dogmática Penal denunciar as inconsistências que o aumento do rigor legal e a criação de novos tipos penais para proteger bens jurídicos de caráter difuso e abstrato propiciaram, apontando as causas e as consequências advindas desse alargamento.

Se, de um lado, novas formas de riscos e perigos foram criadas, sobretudo pelo processo de globalização, o qual, ao mesmo tempo em que promoveu novas possibilidades de segurança global, diversificou as ameaças que pairam sobre os seres humanos e suas variadas formas de interação econômica e social (GIDDENS, 1991, p. 174), de outro, a simples expansão do Direito Penal para proteger interesses até então desconhecidos não se mostrou, na prática, efetiva.

Tradicionalmente concebido para tutelar bens jurídicos concretamente lesionados, o Direito Penal foi desenfreadamente ampliado para alcançar, também, riscos abstratos, sem qualquer preocupação com a (in) compatibilidade de tais interesses com os fundamentos em que se assenta a Dogmática Penal, resultando em inevitável frustração das expectativas depositadas no modelo de persecução penal para servir de antídoto aos problemas novos, além de sobrecarregar o sistema de modo a torná-lo ainda mais ineficiente para lidar com seus antigos dilemas.

Com isso, o ideal de proteção a bens jurídicos relevantes e prevenção a riscos tornou-se mero discurso falacioso, uma "reação simbólica" do legislador frente à criminalidade moderna e organizada, nas palavras de Winfried Hassemer (1994), na medida em que o sistema de justiça criminal nunca foi (e torna-se cada vez menos) capaz de entregar os resultados que dele se espera. E, nas poucas vezes em que é acionado, age de forma traumática e dispendiosa, acarretando, como efeito colateral, custos (não só econômicos, como também sociais) as vezes mais altos do 
que o próprio dano (ou risco de dano) que com ele se pretendia combater. Nas palavras do autor:

O aumento do rigor do Direito penal é marcante, mas sua capacidade de resolver os problemas a que é chamado não está provada, antes, é altamente improvável. Examinando a olho nu, constata-se que o Direito penal se amplia nas mesmas proporções em que crescem os problemas que ele deve solucionar - e naturalmente vice-versa. Especialistas podem enumerar boas razões pelas quais, em seus respectivos campos de atuação, o Direito penal não consegue nem intimidar nem ressocializar. As penas se distanciam, para mais e para menos, de um padrão médio, e os processos penais raramente seguem o curso e atingem seu final, como estabelece o Código de processo penal.

Tudo isso não encontra explicação numa Política criminal pouco enérgica ou numa persecução penal pouco empenhada. A explicação tem raízes mais profundas: o Direito penal não está equipado para alcançar esse tipo de prevenção, e isso, por sua vez, não é por acaso ou por descuido, pelo contrário: organizar o Direito penal para esse tipo de prevenção significa destruí-lo.

[...] O Direito penal preventivo alcança êxito apenas sob a condição de destruir seus próprios fundamentos. Ele é simbólico num mau sentido: não serve, como pretende, à proteção dos bens jurídicos; ele serve apenas àqueles que com ele fazem política. Sua utilização parece mesmo tornar público que os governantes levam a sério as grandes crises da época, pois mostra que eles buscam enfrentá-las com o mais poderoso dos instrumentos: o Direito penal. A longo prazo, esse Direito penal simbólico é destrutivo; a curto prazo, ele atua como sedativo, na medida em que lida com as crises apenas simbolicamente (e, em termos de ambiente e drogas, a situação é de crise mesmo!) e também inibe a busca de soluções reais para elas. A longo prazo, é preciso temer (ou pode-se esperar) que as pessoas, em algum momento, percebam que o rei está nu. (HASSEMER, 2008, p. 298-300).

Diante desse panorama de sobrecarga do sistema de justiça criminal e mau uso de suas ferramentas, ganha relevo a ideia de uma “política criminal orientada pela liberdade”, tal como propugnado por Hassemer (2008, p. 300). Isso não significa abrir mão dos instrumentos 
penais, ainda necessários em relação aos casos mais graves (o que certamente inclui os grandes esquemas de corrupção e lavagem de dinheiro). Significa adotar novos mecanismos de prevenção e controle mais efetivos e menos traumáticos, capazes de melhor lidar com os problemas atuais e entregar resultados que o Direito Penal, da maneira como ainda é usado, não consegue (ou o faz mediante graves violações a direitos e garantias fundamentais).

Especialmente em relação à macrocriminalidade econômica e à corrupção (incluindo os crimes societários), há evidente dificuldade de ordem teórica e prática: a imposição de penas privativas de liberdade pressupõe mecanismos de atribuição pessoal e individual da responsabilidade penal, o que nem sempre é possível quando se trata de infrações praticadas no curso de atividades empresariais, nas quais as participações individuais nos ilícitos muitas vezes não pode ser isolada e aferida (HASSSEMER, 2008, p. 299).

Isso, por si só, revela um contrassenso: adota-se o sistema penal como mecanismo preferencial de solução de conflitos, embora os fundamentos necessários para a imposição de sanções restritivas da liberdade (e a própria prisão, em si) não sejam compatíveis com a grande parte dos crimes de colarinho branco (porquanto geralmente praticados por intermédio de pessoas jurídicas). O remédio é inócuo e causa efeitos colaterais indesejáveis, como bem adverte Silva Sánchez:

O resultado é desalentador. Por um lado, porque a visão do Direito penal como único instrumento eficaz de pedagogia político-social, como mecanismo de socialização, de civilização, supõe uma expansão ad absurdum da outrora ultima ratio. Mas sobretudo porque, ademais, tal expansão é inútil em boa medida, porque submete o Direito penal a cargas que este não pode suportar. Ao menos enquanto se mantiver um modelo mais ou menos análogo ao clássico de garantias e regras de imputação (2011, p. 63, tradução livre).

A situação posta é a seguinte: a corrupção e a macrocriminalidade econômica, por sua própria essência, são mais impermeáveis ao sistema de justiça penal que outras modalidades delitivas. E isso se deve a vários fatores, dentre eles a própria seletividade do aparato judiciário 
(mais bem equipado para lidar com a criminalidade ordinária - os street crimes, ou crimes de rua), o pacto de silêncio característico desses crimes e os elevados índices de subnotificação (provenientes, dentre outros motivos, dos mecanismos de racionalização e justificação dos crimes de colarinho branco e do status social de que gozam os seus infratores, dotados de melhores instrumentos para inocuizar a atuação das instâncias de controle), e a própria incapacidade da justiça criminal para lidar com esses tipos de infração (pelas razões dogmáticas acima delineadas e pela própria sobrecarga do sistema penal, utilizado como modo prioritário de solução de conflitos, e não subsidiário).

Com isso, o Direito Penal não alcança nem sequer o seu propósito preventivo-geral, pois a certeza de sua ineficácia anula os efeitos dissuasivos pretendidos com a mera criação de novos tipos penais e a cominação de sanções restritivas da liberdade, por mais severas que sejam.

Concordamos com Winfried Hassemer quando ele propõe a superação do modelo punitivista em que se assenta o Direito Penal moderno para dar lugar a um sistema de justiça criminal mais voltado à prevenção delitiva, com efeitos não apenas simbólicos e com maior aptidão para enfrentar os novos riscos sociais provenientes da pósmodernidade (dentre os quais se destacam os delitos contra a ordem financeira, crimes contra a Administração Pública e outras modalidades de macrocriminalidade econômica).

Segundo Hassemer, as perspectivas de uma nova política criminal, mais condizente com os problemas atuais, impõem a substituição do que ele denomina "prevenção normativa”, característica do Direito Penal clássico e de natureza meramente simbólica, pela ideia de "prevenção técnica ou organizacional”, que pressupõe a adoção de medidas organizacionais criativas capazes de atingir, com maior efetividade, os fins preventivos que o sistema de justiça criminal deve alcançar, “(...) desenvolvendo instrumentos legais ou favorecendo a aplicação dos já existentes, os quais não apenas simulem seu caráter preventivo mas realmente tenham efeito preventivo" (2008, p. 309).

Tratando especificamente da corrupção enquanto modalidade de criminalidade que merece especial atenção (sem necessariamente abrir mão do aumento do rigor penal, considerando a alta lesividade desse tipo de ilícito e por se tratar de criminalidade organizada, o que justifica 
a imposição de providências mais severas em determinadas situações), sugere o referido autor a adoção de medidas organizacionais criativas de caráter preventivo, como, por exemplo, a criação de canais de denúncias (hot lines) para transmitir à chefia imediata informações relevantes ao desfazimento de elos da cadeira organizacional da corrupção, a realização de inspeções e auditorias capazes de promover a detecção precoce de processos corruptivos, o aperfeiçoamento dos sistemas de registro e intercâmbio de dados, assim como o estímulo à cultura de acesso às informações. "Assim, a prevenção organizada seria a resposta certa à criminalidade organizada e, simultaneamente, acarretaria até mesmo a ampliação dos direitos do cidadão, diferentemente da prevenção normativa, que sempre vem acompanhada de ameaças e corrosões desses direitos" (HASSEMER, 2008, p. 313).

No mesmo sentido, Claus Roxin reconhece o aumento da vigilância estatal em setores estratégicos, como no enfrentamento da macrocriminaladidade econômica e do crime organizado, como parte integrante do Direito Penal do futuro, em que a pena cederá lugar, cada vez mais, a medidas preventivas, reduzindo-se as punições a um núcleo essencial de comportamentos (2012, p. 8-9; 15).

Com isso, abre-se um campo fecundo a novas formas de controle, mais eficientes e menos traumáticas que o Direito Penal clássico, porquanto dissociadas da imposição de penas restritivas de liberdade (ao menos não de forma prioritária), dando lugar a sanções e outros estímulos dissuasivos efetivamente capazes de interromper o processo delitivo e prevenir novas violações a bens jurídicos coletivos.

\section{A PERSECUÇão PENAL dA CORRUPÇÃo NO BRASIL E A INSUFICIÊNCIA DO MODELO ATUAL DE GESTÃo DE CONFLITOS}

As instâncias formais de controle e prevenção à corrupção no Brasil sempre estiveram atreladas à adoção de mecanismos contenciosos de solução de conflitos, mediante instauração de processos (judiciais ou administrativos) cuja finalidade precípua consiste na imposição de uma sanção (multa, pena privativa de liberdade etc.), respeitado o contraditório e o direito de defesa. 
Ao longo das últimas décadas, no entanto, foram incorporadas no sistema judicial brasileiro algumas medidas alternativas à prisão e mecanismos consensuais de solução de litígios, em flagrante mitigação ao outrora absoluto princípio da obrigatoriedade da ação penal pública, a exemplo da transação penal e da suspensão condicional do processo, bem como criou-se um foro específico (juizados especiais criminais) para julgar de modo mais célere e simplificado crimes de menor potencial ofensivo, visando aliviar o sistema carcerário e judicial, evitando que delitos menos graves continuassem a sobrecarregar o Poder Judiciário, o Ministério Público e a polícia judiciária.

Contudo, nenhuma das alterações legislativas ocorridas nas últimas décadas conseguiu solucionar, de modo definitivo, os problemas crônicos do sistema de justiça criminal brasileiro, como a sobrecarga de processos, a morosidade da tramitação processual, a repressão seletiva e a superlotação carcerária. Apesar das reformas, a persecução penal no Brasil continua a não ser uma realidade para a parcela de criminosos pertencente a postos mais privilegiados da sociedade.

De acordo com o mais recente levantamento feito pelo Conselho Nacional de Justiça (2018), somente 1,46\% das pessoas presas estão nessa condição pela prática de crimes contra a Administração Pública, enquanto mais da metade da população carcerária brasileira está atrelada a crimes contra o patrimônio e relacionados ao tráfico de drogas.

Isso evidencia que o sistema de justiça criminal brasileiro direciona o seu aparato repressivo a algumas modalidades delitivas, consideradas mais ofensivas à paz social e que atingem, prioritariamente, apenas aquelas pessoas social e economicamente mais vulneráveis, negligenciando uma boa parte de criminosos, igualmente ou até mais nocivos, porém mais capazes de inocuizar a atuação das instâncias formais (e informais) de controle.

Além da seletividade e direcionamento do aparato repressivo, existem outros gargalos que impedem o bom funcionamento do sistema de justiça criminal no Brasil frente a crimes de corrupção e demais modalidades de crimes de colarinho branco. O primeiro deles é a própria sobrecarga do sistema.

Segundo se infere de relatório diagnóstico divulgado pelo Conselho Nacional de Justiça (2012), com base em dados fornecidos pelos 
Tribunais de Justiça estaduais e federais relativos ao ano de $2011^{3}$, a quantidade de julgamentos, em primeira e segunda instância, de processos criminais envolvendo delitos de corrupção ou lavagem de dinheiro é bastante inferior ao número de denúncias recebidas, correspondendo, no período analisado, a 30\%, no caso da Justiça Estadual, e a cerca de $14 \%$ na Justiça Federal.

TABelA 1. Quantidade de denúncias de corrupção e lavagem de dinheiro recebidas e de julgamentos realizados no ano de 2011

\begin{tabular}{c|c|c|c|c}
\hline $\begin{array}{c}\text { Esfera de } \\
\text { jurisdição }\end{array}$ & $\begin{array}{c}\text { Denúncias } \\
\text { recebidas no } \\
\text { ano de 2011 }\end{array}$ & $\begin{array}{c}\text { Julgamentos } \\
\text { em processos } \\
\text { judiciais no } \\
\text { ano de 2011 }\end{array}$ & $\begin{array}{c}\text { Julgamentos } \\
\text { definitivos em } \\
\text { processos judiciais } \\
\text { no ano de 2011 }\end{array}$ & $\begin{array}{c}\text { Procedimentos } \\
\text { judiciais em } \\
\text { tramitação em } \\
\mathbf{3 1 / 1 2 / 2 0 1 1}\end{array}$ \\
\hline $\begin{array}{c}\text { Justiça } \\
\text { Federal } \\
\text { Justiça } \\
\text { Estadual }\end{array}$ & 1512 & 53 & 30 & 1.137 \\
\hline Total & $\mathbf{1 7 4 1}$ & $\mathbf{6 8 9}$ & 453 & 5.897 \\
\hline
\end{tabular}

Fonte: Conselho Nacional de Justiça, 2012, p. 4;7

3 Trata-se de relatório elaborado antes da aprovação do Novo Código de Processo Civil, que promoveu importantes reformas processuais visando racionalizar o sistema de justiça brasileiro e consolidar mecanismos de solução consensual de litígios. Contudo, a possibilidade de celebração de acordos em ações de improbidade administrativa somente passou a ser admitida com a recém aprovada Lei 13.964, de 24 de dezembro de 2019 ("Pacote Anticrime"), que, ao prever o acordo de não persecução cível (ANPC), revogou expressa vedação legal em sentido contrário. A novel lei também ampliou substancialmente as hipóteses de solução consensual de conflitos penais, ao prever o acordo de não persecução penal (ANPP). Nesse sentido, considerando o panorama legislativo vigente até 2019, quando houve a incorporação desses novos institutos, desde a divulgação do relatório não se verificou qualquer alteração da legislação processual que pudesse justificar uma mudança substancial do quadro revelado nesse levantamento, razão pela qual, dada a carência de estudos específicos mais atualizados e pela própria recenticidade do ANPP e ANPC, esses dados foram apresentados no presente artigo para ilustrar a situação do sistema judicial brasileiro anterior à incorporação de tais mecanismos de solução negocial de litígios no ordenamento jurídico pátrio. 
Verifica-se que o déficit de julgamentos de ações relativas a atos de improbidade administrativa é ainda maior do que o déficit de julgamentos dos processos criminais relativos a casos de corrupção e lavagem de dinheiro. Segundo levantamento do Conselho Nacional de Justiça (2012), a proporção entre o número de julgamentos definitivos e o quantitativo de ações de improbidade recebidas no mesmo ano é bastante inferior, correspondendo a apenas $1 \%$ dos casos, na Justiça Federal, e a $4 \%$ na Justiça Estadual.

TABela 2. Quantidade de ações de improbidade administrativa recebidas e de julgamentos realizados no ano de 2011

\begin{tabular}{c|c|c|c|c|c}
\hline $\begin{array}{c}\text { Esfera de } \\
\text { jurisdição }\end{array}$ & $\begin{array}{c}\text { Ações } \\
\text { recebidas } \\
\text { no ano de } \\
\mathbf{2 0 1 1}\end{array}$ & $\begin{array}{c}\text { Julgamentos } \\
\text { em processos } \\
\text { judiciais no } \\
\text { ano de 2011 }\end{array}$ & $\begin{array}{c}\text { Julgamentos } \\
\text { definitivos } \\
\text { em processos } \\
\text { judiciais no } \\
\text { ano de 2011 }\end{array}$ & $\begin{array}{c}\text { Procedimentos } \\
\text { judiciais em } \\
\text { tramitação em } \\
\mathbf{3 1 / 1 2 / 2 0 1 1}\end{array}$ & $\begin{array}{c}\text { Réus conde- } \\
\text { nados defini- } \\
\text { tivamente }\end{array}$ \\
\hline $\begin{array}{c}\text { Justiça } \\
\text { Federal } \\
\text { Justiça } \\
\text { Estadual }\end{array}$ & 5.739 & 79 & 5 & 4.250 & 4 \\
\hline Total & $\mathbf{6 . 3 1 0}$ & $\mathbf{2 . 1 8 5}$ & $\mathbf{2 5 6}$ & $\mathbf{1 8 . 2 6 5}$ & 264 \\
\hline
\end{tabular}

Fonte: Conselho Nacional de Justiça, 2012, p. 11

Em levantamento mais recente, também realizado pelo Conselho Nacional de Justiça (2020), extrai-se dos indicadores de desempenho das unidades judiciárias com competência especializada/exclusiva que as Varas de Execução Fiscal e das Fazendas Públicas, responsáveis pelo processamento e julgamento de ações de improbidade administrativa e demais ações de ressarcimento ao erário, possuem, dentre todas as unidades especializadas, a maior taxa de congestionamento (percentual de casos que permaneceram pendentes de solução ao final do ano-base, em relação ao número de processos que tramitaram no mesmo período), tendo alcançado índice de $86 \%$. Já as Varas Criminais ocupam o quarto lugar no comparativo, possuindo índice de congestionamento igualmente elevado, de $72 \%$. 
Figura 1. Taxa de congestionamento nas varas exclusivas, por tipo de competência (ano-base 2019)

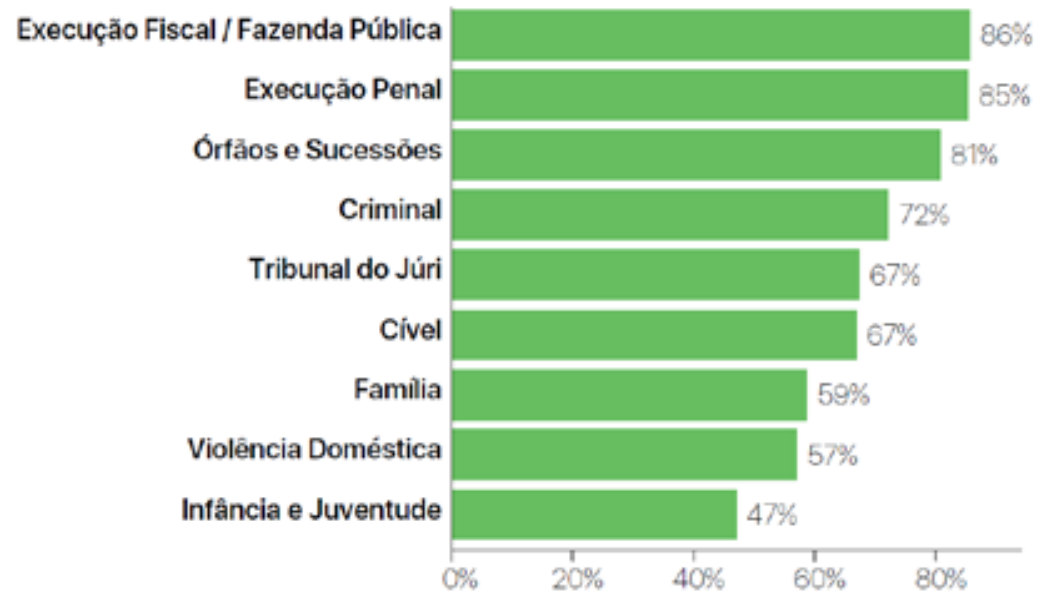

Fonte: Conselho Nacional de Justiça, 2020, p. 199

Outro aspecto importante é o déficit de resultados. Mesmo quando rompidas as elevadas taxas de subnotificação e tais delitos são investigados e denunciados, grande parte dos casos de corrupção acaba não resultando na devida condenação dos envolvidos e restituição dos valores obtidos ilicitamente, seja por motivos de improcedência decorrente de insuficiência probatória, seja por ausência de elementos capazes de quantificar o real prejuízo causado pela infração, seja, ainda, em razão da prescrição, que corresponde ao reconhecimento do sistema judicial de sua própria ineficiência para resolver os conflitos em tempo hábil. A propósito, mais de $20 \%$ das ações penais de competência originária dos tribunais são extintas por prescrição $0^{4}$.

4 Segundo levantamento do Conselho Nacional de Justiça (2012, p. 21), no período de 01 de janeiro de 2010 a 31 de dezembro de 2011, foram proferidas pelos tribunais de segunda instância (estaduais e federais) 5.797 decisões reconhecendo a extinção de punibilidade em razão da prescrição da pretensão punitiva, o que corresponde a $20,8 \%$ dos 27.806 processos criminais de competência originária dos tribunais por foro de prerrogativa de função em tramitação no período. 
O tempo de duração dos processos judiciais destinados a apuração de atos de corrupção também revela a ineficiência do Poder Judiciário brasileiro para enfrentar o problema. Conforme diagnóstico feito pelo Conselho Nacional de Justiça (2012) referente ao ano de 2011, o tempo médio de duração dos processos relativos a atos de improbidade administrativa na Justiça Federal, compreendido entre o recebimento da ação e a data do julgamento definitivo, foi contabilizado em 4 anos e 11 meses, enquanto na Justiça Estadual o tempo de julgamento verificado foi de 6 anos e 6 meses.

Esses dados traduzem em números o baixo índice de resolutividade e o grau de morosidade do sistema de justiça brasileiro, que, diferentemente de países com sistemas de maior cultura negocial (a exemplo dos Estados Unidos, onde a taxa de solução consensual de litígios chega a 95\% dos casos) e a despeito das recentes reformas processuais destinadas a implantar mecanismos de solução consensual de litígios ${ }^{5}$, ainda possui índice geral de conciliação (percentual de sentenças e decisões resolvidas por homologação de acordo em relação ao total de sentenças e decisões terminativas proferidas) muito baixo, de apenas 12,5\%, conforme último levantamento feito pelo Conselho Nacional de Justiça (2020, p. 172).

Todos esses gargalos, aliados às dificuldades teóricas e práticas relacionadas à persecução penal dos crimes de colarinho branco, evidenciam a insuficiência do sistema judicial brasileiro para lidar com os casos de corrupção e delitos macroeconômicos.

Como efeito disso, cultiva-se na sociedade brasileira um sentimento de impunidade e descrédito nas instituições retroalimentado a cada caso de corrupção não solucionado e que se mostra deletério aos padrões éticos que devem nortear o comportamento de cidadãos e cidadãs. Afinal, se "sistemas claros de regras e punições, junto com uma imposição

5 A propósito, verifica-se que o índice geral de conciliação variou muito pouco de 2015 a 2019 , saindo de $11,1 \%$ naquele ano para $12,5 \%$ neste último (Conselho Nacional de Justiça, 2020, p. 172), o que demonstra que a série de mudanças implementadas recentemente, notadamente com a entrada em vigor do Novo Código de Processo Civil, ainda não foi suficiente para produzir mudanças significativas. Resta saber se as recentes reformas promovidas pela Lei 13.964 ("Pacote Anticrime"), que introduziu o ANPP e o ANPC, surtirão maior efeito, especialmente no tratamento conferido à corrupção em âmbito judicial. 
rigorosa, podem fazer diferença para os padrões de comportamento", como bem adverte Amartya Sen (2010, p. 351), a apatia judicial e a ausência de sancionamento a indivíduos que pratiquem atos de corrupção amplamente noticiados certamente provocam reação inversa.

Diante desse cenário de elevada impunidade e seletividade, especialistas passaram a reconhecer a necessidade de promover novas formas de enfrentamento aos crimes de colarinho branco, privilegiando a adoção de medidas assecuratórias patrimoniais, sanções pecuniárias, confisco de bens (o que incluiria a polêmica proposta de confisco alargado) e outras penas restritivas de direitos em detrimento da imposição, hipotética e improvável, de penas privativas de liberdade (LIVIANU, 2014, p. 135).

Trata-se de estratégia alinhada a determinações oriundas de organismos internacionais e que, se devidamente efetivadas, podem contribuir para interromper cadeias criminosas altamente organizadas, cujo êxito de sua atuação repousa justamente na livre disposição de elevadas cifras, proveniente de meios ilícitos e que financiam a própria continuidade da atividade criminosa.

Contudo, a mera inserção, mediante reforma legislativa, de novos instrumentos destinados ao combate da corrupção e da criminalidade organizada não produzirá qualquer efeito prático se mantidas as mesmas estruturas em que se assenta o sistema de justiça penal brasileiro, marcado por fórmulas processuais burocráticas e de questionável eficácia, incompatíveis com a dinâmica da sociedade moderna.

Partilhando entendimento favorável à instituição de mecanismos consensuais de solução de conflitos penais, Suxberger e Filho afirmam que:

Diante do quadro de expansão do direito penal, verifica-se uma dependência da justiça negociada, por razões diversas. Não somente a gestão financeira identifica o interesse da Política Criminal Estatal, mas, também, na dinâmica da sociedade moderna, parece não existir mais espaço para um processo penal burocrático, ineficiente e moroso, como instrumento de concretização do direito material no quadro da criminalidade complexa e organizada. Os procedimentos processuais, com a repetição de atos desnecessários, não se coadunam com a velocidade da comunicação da sociedade moderna. (2016, p. 387). 
Afinal, soluções criativas, céleres e efetivas são incompatíveis com modelos cartorários, morosos e estanques, como o sistema de persecução penal adotado no Brasil.

\section{A CONSENSUALIDADE COMO ESTRATÉGIA POLÍTICO-CRIMINAL NO ENFRENTAMENTO À CORRUPÇÃO E À MACROCRIMINALIDADE ECONÔMICA}

Nos últimos anos, o Brasil vivenciou uma série de reformas legislativas destinadas a aperfeiçoar o sistema de controle e sancionamento da corrupção, da criminalidade organizada e demais infrações contra a ordem financeira e econômica.

Um dos mais importantes avanços consistiu na Lei Anticorrupção (Lei $\mathrm{n}^{\circ} 12.846$, de $1^{\circ}$ de agosto de 2013), que representa o grande marco legal para a "autorregulação regulada" em matéria de corrupção no Brasil, ao possibilitar a realização de acordos de leniência e estimular a instituição de mecanismos e procedimentos internos de integridade, auditoria e incentivo à denúncia de irregularidades.

Ao inaugurar um regime específico de sancionamento a pessoas jurídicas que pratiquem atos de corrupção, a referida lei aproxima-se, na visão de alguns autores, de uma espécie de sistema administrativo sancionador (VERÍSSIMO, 2017), cuja finalidade, nas palavras de seu idealizador, consistiria em "[...] ordenar, de modo geral, setores de atividade (reforçar, mediante sanções, um determinado modelo de gestão setorial)" (SILVA SANCHEZ, 2011, p. 137, tradução livre). Ainda nas palavras do autor:

Como indicado, o Direito administrativo sancionador é o reforço da ordinária gestão da Administração. Assim, caberia afirmar que é o Direito sancionador de condutas perturbadoras de modelos setoriais de gestão. Seu interesse reside na globalidade do modelo, no setor em sua integralidade, e por isso tipifica infrações e sanciona desde perspectivas gerais. Não se trata aqui do risco concreto como risco em si mesmo relevante e imputável pessoalmente a um sujeito determinado, mas sim o fator determinante é a visão macroeconômica ou macrossocial (as "grandes cifras"; o "problema estrutural" ou "sistêmico"). (SILVA SANCHEZ, 2011, p. 137, tradução livre). 
Dessa forma, tratando-se de atos de corrupção ou infrações a ordem econômica e financeira praticados no contexto empresarial, abriuse a possibilidade de direcionamento do aparato estatal para sancionar a própria pessoa jurídica, impondo-se medidas efetivas e capazes de coibir e prevenir o desvirtuamento das atividades empresariais, em vez de centrar esforços na persecução penal de seus sócios ou diretores, fadada ao fracasso, em razão da evidente incompatibilidade dos fundamentos do Direito Penal clássico com delitos societários e demais dificuldades de ordem prática, já mencionados neste trabalho.

Outra mudança importante ocorreu com a Lei de Organização Criminosa (Lei ${ }^{\circ} 12.850$, de 2 de agosto de 2013), que incorporou alguns institutos difundidos internacionalmente para o enfrentamento da criminalidade organizada e demais delitos macroeconômicos, como a celebração de acordos de colaboração premiada com pessoas acusadas ou investigadas integrantes da organização que contribuam de forma voluntária e efetiva com a investigação ou o processo criminal. Dentre os resultados advindos da colaboração que autorizam a celebração do acordo, encontra-se a prevenção de infrações penais decorrentes das atividades da organização criminosa e a recuperação total ou parcial do produto ou proveito das infrações penais praticadas no curso da atividade ilícita.

Finalmente, outra grande inovação legislativa ocorreu com a recente aprovação do "Pacote Anticrime" (Lei n ${ }^{\circ}$ 13.964, de 24 de dezembro de 2019), que alterou substancialmente o sistema processual brasileiro, ao ampliar os mecanismos de solução consensual de conflitos na esfera criminal, mediante acordos de não persecução penal (ANPP) em relação a delitos com pena mínima inferior a quatro anos (o que abrange a maioria dos crimes contra a Administração Pública, bem como o crime de lavagem de capitais).

De acordo com a novel lei, a celebração de tais acordos está condicionada à confissão, à reparação integral do dano (salvo manifesta impossibilidade de fazê-lo), à renúncia a bens e direitos obtidos como produto ou proveito do crime, além do cumprimento de prestação de serviços à comunidade, prestação pecuniária ou outra medida indicada pelo Ministério Público, desde que proporcional e compatível com a infração imputada. 
A mesma lei também passou a autorizar expressamente a celebração de acordos de não persecução cível (ANPC) nas ações que versam sobre atos de improbidade administrativa, superando antiga proibição expressa de transação, acordo ou outras formas de conciliação nas ações destinadas a apurar tais infrações.

Essas reformas legislativas, sobretudo as alterações promovidas pela Lei $\mathrm{n}^{\circ} 13.964$, na esteira de outros instrumentos legislativos anteriores, caminham em direção à consolidação de uma nova ordem processual, marcada pela solução consensual de litígios e ruptura parcial com o princípio da obrigatoriedade da ação penal, visando imprimir maior racionalidade e efetividade ao sistema de justiça criminal. Em verdade, sob uma perspectiva mais ampla, o acordo de não-persecução penal, por exemplo, não é em si uma inovação total no sistema processual penal brasileiro. Mais adequado seria categorizá-lo como uma nova roupagem à transação penal (art. 76, da Lei 9.099/95).

De todos os aspectos relativos ao ANPP, trazido pela Lei 13.964/2019, a necessidade de confissão (de questionável constitucionalidade) é, sem dúvida, o maior ponto controvertido, pois, ao exigir a confissão, a lei confere à pessoa acusada dispor do devido processo legal, o que, dado o peso probatório que os juízes e as juízas atribuem à auto-atribuição da culpa, em síntese, muitas vezes, implicará o risco de produção prova contra si, algo inaceitável. Situação essa plenamente factível em um sistema penal, como o brasileiro, orientado pela seletividade (MENDES e MARTÍNEZ, 2020) ${ }^{6}$. Não se desconhece, portanto, que os acordos de não-persecução somente se possam dar legal e regularmente

6 Como apontam Mendes e Martinez (2020) basta imaginar "um dos tantos rincões brasileiros, onde não há defensoria pública, no qual alguém, com o justo receio de que possa responder a um processo criminal (que, por certo, durará anos), confesse falsamente para obter um acordo de não-persecução penal. Posteriormente, não tendo condições de, por exemplo, arcar com os valores da prestação pecuniária que lhe foi exigida como parte do acordo, venha a ser formalmente processado sendo que sua confissão sobre o crime que não cometeu já se encontra nos autos.” Em conclusão como advertem as autoras, em muitos casos em "um sistema penal como o nosso, no qual a defesa técnica inexiste para a maior parte da população carcerária composta por homens e mulheres, pretos, pobres e de baixíssima escolaridade pensar a possibilidade de "acordos" entre "defesa" e Ministério Público não passa verdadeiramente de um eufemismo para prisão." 
na medida em que a pessoa investigada disponha de real oportunidade de negociação, o que implica plenitude de acesso à defesa ainda nesta fase.

Por outro lado, em que pese a análise da constitucionalidade deste dispositivo ainda depender de manifestação de nossa Corte Suprema, convém registrar que, no plano dos fatos, quanto aos crimes de corrupção e outros que envolvem a macrocriminalidade econômica, por, inclusive, muitas das razões já expostas neste artigo, o risco de confissões falsas (ou obtidas sob pressão) e encarceramento indevido será de improvável ou impossível verificação. De qualquer sorte, é de resguardar-se aqui, portanto, as pertinentes e necessárias críticas de ordem criminológica decorrentes da seletividade dos sistemas.

Feitas essas considerações, é de ver-se que as inovações trazidas com a inclusão do acordo de não persecução penal provocarão profundas mudanças na forma de atuação dos órgãos integrantes do sistema de justiça, mormente o Ministério Público e o Poder Judiciário, enquanto instituições responsáveis pela concretização de políticas criminais no âmbito jurisdicional, no exercício de seus respectivos poderes de persecutio criminis e jus puniendi estatal, de modo a adequarem-se ao novo panorama normativo, que privilegia a solução consensual de conflitos em detrimento do antigo paradigma essencialmente litigioso.

A base de justificação da justiça negocial, como bem descreve Vinicius Vasconcellos, decorre da chamada "crise do processo penal", a qual resulta do confronto entre o processo de expansão penal e a insuficiência de recursos econômicos, acarretando a frustração dos clamores punitivos da sociedade (2020a, p. 162), que não vê os conflitos serem solucionados com a mesma proporção com que são percebidos na vida cotidiana e previstos pela própria legislação.

Para o referido autor, a busca pela celeridade nos julgamentos de casos penais, regrada por posturas eficientistas, traz como consequências a relativização das regras do devido processo penal e a violação de direitos penais do acusado, acarretando a perda da essência do processo penal, que deixa de ser uma limitação ao poder punitivo estatal (VASCONCELLOS, 2020a, p. 163).

Refutando a crítica de que o modelo negocial provém de um discurso eficientista de ruptura com as premissas do processo penal democrático, Suxberger e Filho afirmam que tal posicionamento constitui 
expressão de um garantismo com viés essencialmente negativo, que também termina por negar o postulado da proibição da tutela penal deficiente (2016, p. 391).

De todo modo, as críticas à possível vulneração dos valores consagrados pelo direito penal de matriz liberal aplicam-se com maior autoridade aos modelos de justiça criminal que reconhecem a possibilidade de imposição de sanções privativas de liberdade sem o devido processo penal (como ocorre no sistema estadunidense e, no Brasil, apenas no caso dos acordos de colaboração premiada). Nessa hipótese, a importação de mecanismos negociais como a “'barganha penal” deve ser compatibilizada com o ordenamento jurídico pátrio, guardando estrita observância aos direitos e garantias constitucionais (VASCONCELLOS, 2020a, p. 170-171).

Contudo, as mesmas críticas não parecem incidir (ao menos não com a mesma proporção) nos modelos de persecução penal de viés essencialmente preventivo, orientados pela liberdade e pelo consenso, cuja imposição de penas restritivas de liberdade dá-se somente em caráter subsidiário e sem prescindir do devido processo penal (nos casos de infrações dotadas de maior gravidade ou caso frustrada a solução negocial do conflito). É este o modelo inaugurado com a Lei no 13.964 , que incorporou ao ordenamento jurídico brasileiro a figura do acordo de não persecução penal.

Ressalvadas as controvérsias de cunho dogmático, a implementação de mecanismos consensuais de solução de conflitos acarreta inúmeras vantagens de ordem pragmática, dentre as quais se destaca a própria garantia de efetividade, porquanto possui como requisito de admissibilidade a confissão do infrator e a sua concordância com as medidas impostas como condição para a celebração do acordo. Nenhuma medida de caráter preventivo será tão ou mais efetiva do que aquelas que contem com a anuência do seu destinatário. Este, em contrapartida, passa a dispor da oportunidade de amenizar os custos (econômicos, sociais e até psicológicos) ocasionados pela acusação formal, fator que, dentro de uma perspectiva lógico-racional que rege a criminalidade macroeconômica, irá influenciar positivamente para a realização do acordo.

Com isso, pode-se afirmar que a previsão de acordos penais representa uma ruptura ao paradigma punitivista, na medida em que substitui a ideia de repressão por um conceito racional de prevenção, 
por intermédio do qual se acentuam a necessidade e a legitimidade das formas de solução baseadas na economia processual e orientadas pelo consenso, possibilitando o fortalecimento das normas e da dinâmica de ressocialização, que não pode ser obtido com a mesma legitimação por meio do processo penal tradicional (SCHÜNEMANN, 2002, p. 294).

Claro que a busca por decisões consensuais traz evidentes dificuldades de ordem prática e demanda concessões mútuas (com o agravante de que uma das partes envolvidas, no caso o Ministério Público, representa interesses de caráter indisponível, o que limita consideravelmente a sua margem de negociação, na medida em que sempre deverá pautar a sua atuação no ressarcimento integral do dano e na imposição de medidas alternativas à prisão suficientes à punição e prevenção do crime). Acrescente-se que a discricionariedade do órgão acusador reside, tão somente, na forma de resolução do caso (ou seja, na resposta estatal ao ilícito praticado, dentro das balizas impostas por lei), pressupondo, assim como antes, a existência de justa causa e suporte probatório mínimo, porquanto a implementação de modelos de resolução negocial de conflitos na seara criminal não importa em total ruptura com o princípio da obrigatoriedade/legalidade que ainda orienta a persecução penal no Brasil (BRANDALISE, 2016, p. 171).

Em outras palavras, as reformas processuais empreendidas até então não conferem amplos espaços de conveniência e oportunidade ao Ministério Público no exercício de sua atividade persecutória, não podendo deixar de serem oferecidas denúncias (resguardada a possibilidade de acordo de não persecução penal, quando cabível) por critérios distintos da existência e comprovação do delito (VASCONCELLOS, 2020b, p. 248). Isso, por si só, nos diferencia do modelo estadunidense, marcado por ampla discricionariedade do órgão acusador, tornando incabível a simples reprodução no Brasil de inúmeras críticas feitas ao sistema de barganha penal norte-americano, notadamente no que concerne ao grau de coercibilidade das propostas, como apontam Suxberger e Filho (2016, p. 390).

Contudo, uma vez superados os gargalos que hoje impedem o regular funcionamento do sistema de justiça criminal (o que as reformas legislativas pretendem alcançar a médio prazo, mediante diminuição das taxas de congestionamento, por meio do aumento da solução precoce e consensual de conflitos), tais empecilhos deixarão de existir, porquanto 
a celebração de acordos de não persecução penal, nos casos em que couberem, representarão alternativa mais vantajosa ao infrator (especialmente em relação aos crimes de colarinho branco), do que o risco de uma condenação criminal (e seus efeitos estigmatizantes), decorrente de um processo judicial com tramitação mais célere e com desfecho desfavorável ao réu mais provável (se devidamente equalizado o volume de julgamentos em relação à quantidade de denúncias oferecidas).

Nesse novo sistema processual, compete ao Ministério Público a gestão de sua atividade persecutória, oportunizando-lhe centrar os esforços investigativos em casos mais graves, em que a celebração de acordos não se revele suficiente para restabelecer o status quo ante e prevenir a prática de novos ilícitos, demandando medidas mais severas, seja privativas de liberdade, seja interdição de direitos, a serem decretadas pelo Poder Judiciário.

Da mesma forma, cria-se para o Ministério Público um ambiente próspero ao planejamento de suas ações, facultando-lhe a gestão dos casos levados ao seu conhecimento e o exercício, com maior efetividade, de sua atuação preventiva, a ser considerada quando da celebração de acordos de não persecução penal, mediante imposição de medidas alternativas à prisão dotadas de efeito preventivo concreto, e não meramente simbólico, tal como propugnado por Winfried Hassemer.

Neste ponto, cumpre salientar que o enfrentamento à corrupção e à macrocriminalidade econômica pressupõe mecanismos criativos de fiscalização e sistemas efetivos de controle e sancionamento que sejam capazes de inibir os estímulos favoráveis ao crime, mediante incremento dos custos e riscos relacionados à atividade criminosa.

Assim, em casos de infrações contra a Administração Pública e outros ilícitos macroeconômicos (cometidos pessoalmente ou por intermédio de pessoas jurídicas), podem ser impostas nos acordos de não persecução penal (e cível) medidas de caráter preventivo que sejam efetivamente capazes de coibir a prática de novos ilícitos, como a implementação na pessoa jurídica infratora de programas de integridade (com auditorias independentes e periódicas, treinamentos e capacitações para promover a ética corporativa, criação de fluxos de recebimento e tratamento de denúncias etc.), financiamento de programas educativos e de assistência a vítimas ou de projetos e obras públicas relacionadas 
aos interesses lesados com a infração, dentre outras medidas criativas, a serem estipuladas pelo Ministério Público como condição para celebração do acordo.

Também são superadas as críticas ao uso do sistema criminal para tutelar bens jurídicos abstratos e a utilização de instrumentos sancionatórios tipicamente penais para combater infrações praticadas no seio de atividades empresariais, na medida em que a repressão a tais ilícitos deve passar a ser exercida, prioritariamente, por meio de sistemas próprios de controle e sancionamento, resguardando-se ao Direito Penal apenas os casos mais graves, assegurando, com isso, o seu caráter de ultima ratio.

Esse novo ordenamento processual também deverá impactar a atuação do Poder Judiciário, a quem compete homologar os acordos celebrados, de modo a aferir a voluntariedade e a suficiência das condições impostas para a garantir a repressão e prevenção delitiva. Dessa forma, caso a solução consensual de conflitos atinja os índices desejáveis, espera-se uma redução acentuada das atividades instrutórias e decisórias, as quais passarão a ser exercidas apenas nos casos em que não seja cabível ou restem frustradas as tentativas de acordo, possibilitando aos magistrados uma melhor gestão de seus acervos processuais e, com isso, maior racionalidade no exercício da atividade jurisdicional como um todo.

Destaca-se o importante papel que desempenham as sentenças judiciais no processo de gestão da política criminal, posto que dotadas de dimensão comunicativa geral, na medida em que atualizam a mensagem legislativa e o seu conteúdo mediante interpretações adaptativas ao caso concreto, além de reforçarem a própria obrigatoriedade dos preceitos incriminadores violados (BINDER, 2012, p. 176-177).

Por tal razão, torna-se imprescindível garantir a plena efetividade da atividade jurisdicional, haja vista que os entraves ao regular funcionamento do Poder Judiciário e o déficit de resultados deles decorrentes, especialmente no trato de questões relacionadas à corrupção e à macrocriminalidade econômica, transmitem uma indesejável mensagem de relativização desses ilícitos e de baixa coercitividade das normas incriminadoras, representando verdadeiro estímulo aos criminosos de colarinho branco, que, ao analisar os riscos de suas atividades criminosas, consideram como pouco provável uma condenação. 
A celebração de acordos de não persecução, desde que assegurem o ressarcimento dos danos provocados pela infração e submetam o infrator ao cumprimento de medidas não privativas da liberdade compatíveis com a reprovabilidade da conduta, podem amenizar os efeitos nefastos decorrentes da atual apatia do Poder Judiciário frente à corrupção e macrodelinquência, porquanto a perda dos bens obtidos de forma ilícita e a imposição de sanções pecuniárias, restritivas de direitos e demais penas alternativas atendem ao propósito de reafirmar a coercibilidade e generalidade das normas proibitivas, o que certamente não ocorre nos casos não denunciados, julgados improcedentes ou prescritos, que transmitem mensagem oposta.

\section{Considerações Finais}

A criminalidade do colarinho branco possui racionalidade própria, orientando-se a pessoa infratora de modo deliberado e organizado, mediante análise dos riscos e benefícios da atividade ilícita, conforme revelam os estudos criminológicos sobre essa modalidade delitiva.

Dessa forma, uma política criminal voltada à efetividade do enfrentamento à macrocriminalidade econômica deve necessariamente considerar os fatores que norteiam o comportamento dos criminosos de colarinho branco, de modo a reduzir as condições favoráveis ao delito, impondo riscos à atividade ilícita que a tornem menos atrativa.

O alargamento do Direito Penal para tutelar bens jurídicos abstratos, mediante criminalização de condutas potencialmente lesivas a interesses coletivos, não se revelou, por si só, suficiente para coibir os riscos decorrentes das novas modalidades de interação social e econômica advindas da globalização, em virtude de incompatibilidades de ordem dogmática e a própria seletividade do sistema de justiça criminal, que não costuma atingir determinados setores da sociedade, mais imunes às instâncias de controle e menos suscetíveis aos efeitos estigmatizantes da condenação.

Por tal razão, o tratamento do fenômeno corruptivo e da macrocriminalidade econômica demanda novas estratégias político-criminais, que reconheçam a falibilidade do sistema de justiça criminal para lidar com tais modalidades delitivas e que seja efetivamente capaz de prevenir a ocorrência de novos ilícitos. 
Diante da comprovada ineficiência do modelo tradicional, a instituição de mecanismos consensuais de solução de conflitos apresenta-se como alternativa promissora, na medida em que possibilita, a um só tempo, uma melhor racionalização das atividades de persecução penal e jurisdicionais, além de permitir soluções mais céleres, criativas e adequadas a cada caso, traduzindo-se em respostas efetivas de repressão e prevenção a atos ilícitos.

A coercibilidade das normas proibitivas pressupõe sistemas de controle efetivos, que, sempre que acionados, sejam capazes de reafirmar a validade das regras e valores violados.

O enfrentamento à corrupção e à macrocriminalidade econômica não deve se resumir a fórmulas processuais que tenham como única finalidade a imposição de penas restritivas de liberdade, pois, além das dificuldades de natureza dogmática, tal modelo de justiça não é capaz de fornecer soluções em tempo hábil nem prevenir, de modo abrangente, a ocorrência de novos ilícitos.

Por tal razão, torna-se premente que a atividade persecutória do Estado volte-se, prioritariamente, à imposição de medidas pecuniárias, restritivas de direitos e outras condições adequadas à repressão e prevenção delitiva, as quais podem ser infligidas ao infrator mediante acordo celebrado com o Ministério Público, prescindindo de processos judiciais morosos e de questionável resolutividade.

Ademais, a complexidade das infrações contra a ordem econômica e financeira e o seu caráter difuso, nem sempre passível de individualização, demanda a atuação de sistemas específicos de controle e sancionamento, mais abertos e dinâmicos (dissociados da dogmática jurídico-penal tradicional e de seus fundamentos), e que sejam capazes de promover uma tutela efetiva e integral dos interesses coletivos, produzindo efeitos preventivos e restauradores reais, e não meramente simbólicos, nos moldes propugnados por Winfried Hassemer e Jesus-María Silva Sánchez, restringindo-se o uso de penas privativas de liberdade aos casos mais graves, em que seja possível a atribuição pessoal de responsabilidade criminal.

Para tanto, deverá haver uma maior integração dos órgãos de controle que permita o regular funcionamento das distintas instâncias de sancionamento (responsabilidade por improbidade administrativa, responsabilidade de pessoas jurídicas por atos de corrupção e responsabilidade 
penal), de forma a imprimir um tratamento multisetorial, complementar, abrangente e efetivo aos casos de corrupção e infrações macroeconômicas, sem incorrer em abusos ou violações de direitos individuais.

Feitas tais considerações, é possível concluir que as recentes reformas legislativas ocorridas no Brasil, não apenas no âmbito cível como também na esfera criminal, trouxeram importantes avanços para o enfrentamento da corrupção e da macrocriminalidade econômica, inaugurando uma nova ordem processual, marcada pela superação de modelos primordialmente punitivistas e contenciosos em prol de um sistema mais dinâmico, que priorize mecanismos consensuais de solução de litígios e, com isso, concretize os ideais de efetividade e prevenção.

Entretanto, faz-se necessária uma remodelação da forma de atuação dos órgãos integrantes do sistema de justiça a quem incumbe a efetivação de políticas criminais em âmbito jurisdicional, especialmente o Ministério e o Poder Judiciário, para que se adequem a essa nova realidade, rompendo antigos modelos de atuação que se mostraram ineficazes e explorando os novos instrumentos colocados à sua disposição para, por meio de soluções criativas e resolutivas, consagrar os novos paradigmas da consensualidade e da prevenção.

\section{REFERÊNCIAS}

BARATTA, Alessandro. Criminologia Crítica e Crítica do Direito Penal: introdução à sociologia do direito penal. Tradução de Juarez Cirino dos Santos. 6 ed. Rio de Janeiro: Revan, 2011.

BINDER, Alberto. Análisis político criminal. 1 ed. Bogotá: Astrea, 2012.

BRANDALISE, Rodrigo da Silva. Justiça penal negociada: negociação de sentença criminal e princípios processuais relevantes. Curitiba: Juruá, 2016.

CONSELHO NACIONAL DE JUSTIÇA. Banco Nacional de Monitoramento de Prisões - BNMP 2.0: Cadastro Nacional de Presos. Brasília, 2018. Disponível em: <https://www.cnj.jus.br/wp-content/uploads/2018/01/57412abdb54eba909b3e1819fc4c3ef4.pdf >. Acesso em: 17 mar. 2020.

CONSELHO NACIONAL DE JUSTIÇA. Novos diagnósticos do enfrentamento da corrupção. Brasília, 2012. Disponível em: <https://www.cnj.jus.br/wp-content/ uploads/2011/02/rel_diag_improbidade.pdf >. Acesso em: 19 mar. 2020. 
CONSELHO NACIONAL DE JUSTIÇA. Justiça em Números 2020: ano-base 2019. Brasília, 2020. Disponível em: <https://www.cnj.jus.br/wp-content/uploads/2020/08/ WEB-V3-Justi\%C3\%A7a-em-N\%C3\%BAmeros-2020-atualizado-em-25-08-2020. pdf>. Acesso em: 31 ago. 2020.

FERRAZ JUNIOR, Jairton. Análise criminológica da corrupção: uma visão despenalizante. Revista Brasileira de Ciências Criminais, São Paulo, v. 134, ano 25, p. 109-134, ago. 2017.

GIDDENS, Anthony. As consequências da modernidade. Tradução de Raul Fiker. São Paulo: Editora da Universidade Estadual Paulista, 1991.

HASSEMER, Winfried. Direito Penal: fundamentos, estrutura, política. Tradução de Adriana Beckman Meireles et. al. Porto Alegre: Sergio Antonio Fabris Editor, 2008.

HASSEMER, Winfried. Perspectivas de uma Moderna Política Criminal. Revista Brasileira de Ciências Criminais, São Paulo, v. 8, p. 41-51, out/dez. 1994.

LIVIANU, Roberto. Corrupção - Incluindo a Lei Anticorrupção. 2 ed. São Paulo: Quartier Latin, 2014.

MACHADO, Bruno Amaral; QUEZADO, Marina. Corrupção pública pelos olhos da criminologia: dano social e violação dos direitos humanos. Revista de Estudos Criminais, São Paulo, ano XVII, n. 70, p. 133-174, 2018.

MAURO, Carlos Eduardo Evangelisti. Uma análise da corrupção pública a partir da racionalidade e da ação. Revista de Economia \& Relações Internacionais, v. 1, n. 2, jan. 2003. Disponível em: <http://www.mbafaap.com.br/revista_faap/ rel_internacionais/economia_relacoes_internacionais.htm>. Acesso em: 25 mar. 2020 .

MENDES, Soraia da Rosa; MARTÍNEZ, Ana Maria. Pacote Anticrime: comentários críticos à Lei 13.964/2019. São Paulo: Atlas, 2020.

ROXIN, Claus. Estudos de direito penal. Traduzido por Luís Greco. 2 ed. Rio de Janeiro: Renovar, 2008.

SEN, Amartya. Desenvolvimento como Liberdade. Tradução de Laura Teixeira Motta. São Paulo: Companhia das Letras, 2010.

SHECAIRA, Sérgio Salomão. Criminologia. 7 ed. São Paulo: Thomson Reuters Brasil, 2018.

SCHUNEMANN, Bernd. Temas actuales y permanentes del Derecho penal después del milenio. Madrid: Tecnos, 2002. 
SILVA SÁNCHEZ, Jesús María. La expansión del Derecho penal. Aspectos de la Política criminal en las sociedades postindustriales. Madrid: Edisofer, 2011.

SUTHERLAND, Edwin H. Crime de colarinho branco: versão sem cortes. Traduzido por Clécio Lemos. 1 ed. Rio de Janeiro: Revan, 2015.

SUXBERGER, Antonio Henrique Graciano; FILHO, Dermeval Farias Gomes. Funcionalização e expansão do Direito Penal: o Direito Penal negocial. Revista de Direito Internacional, Brasília, v. 13, n. 1, p. 377-396, 2016. https://doi. org/10.5102/rdi.v13i1.4097

VASCONCELLOS, Vinicius Gomes de. As tendências de expansão da justiça criminal negocial em âmbito internacional: a barganha como instituto importado em convergências entre sistemas. Revista de Estudos Criminais, Porto Alegre, v. 19, n. 76, p. 153-173, 2020.

VASCONCELLOS, Vinicius Gomes de. Colaboração premiada e negociação na justiça criminal brasileira: acordos para aplicação de sanção penal consentida pelo réu no processo penal. Revista Brasileira de Ciências Criminais, São Paulo, v. 166, ano 28, p. 241-271, abr. 2020.

VERÍSSIMO, Carla. Compliance: incentivo à adoção de medidas anticorrupção. 1 ed. São Paulo: Saraiva, 2017. 


\section{Informações adicionais e declarações dos autores (integridade científica)}

Declaração de conflito de interesses (conflict of interest declaration): os autores confirmam que não há conflitos de interesse na realização das pesquisas expostas e na redação deste artigo.

Declaração de autoria e especificação das contribuições (declaration of authorship): todas e somente as pessoas que atendem os requisitos de autoria deste artigo estão listadas como autores; todos os coautores se responsabilizam integralmente por este trabalho em sua totalidade.

- Soraia da Rosa Mendes: projeto e esboço inicial (conceptualization), desenvolvimento da metodologia (methodology), levantamento bibliográfico (investigation), revisão bibliográfica (investigation), redação (writing original draft), participação ativa nas discussões dos resultados (validation), revisão crítica com contribuições substanciais (writing - review and editing), aprovação da versão final.

- Augusto César Borges Souza: projeto e esboço inicial (conceptualization), desenvolvimento da metodologia (methodology), levantamento bibliográfico (investigation), revisão bibliográfica (investigation), redação (writing original draft), participação ativa nas discussões dos resultados (validation), revisão crítica com contribuições substanciais (writing - review and editing), aprovação da versão final.

Declaração de ineditismo e originalidade (declaration of originality): os autores asseguram que o texto aqui publicado não foi divulgado anteriormente em outro meio e que futura republicação somente se realizará com a indicação expressa da referência desta publicação original; também atestam que não há plágio de terceiros ou autoplágio. 
Dados do processo editorial

(http://www.ibraspp.com.br/revista/index.php/RBDPP/about/editorialPolicies)

- Recebido em: 27/04/2020

Equipe editorial envolvida

- Controle preliminar e verificação de plágio:

- Editor-chefe: 1 (VGV) 27/06/2020

- Avaliação 1: 13/07/2020

- Editor-associado: 1 (RO)

- Avaliação 2: 24/07/2020

- Revisores: 3

- Avaliação 3: 15/08/2020

- Decisão editorial preliminar: 23/08/2020

- Retorno rodada de correções: 02/09/2020

- Decisão editorial final: 08/09/2020

\section{COMO CITAR ESTE ARTIGO:}

MENDES, Soraia R.; SOUZA, Augusto C. B. O acordo de não persecução penal e o paradigma da prevenção no enfrentamento à corrupção e à macrocriminalidade econômica no Brasil: novas alternativas ao modelo punitivista tradicional. Revista Brasileira de Direito Processual Penal, Porto Alegre, vol. 6, n. 3, p. 1175-1208, set./ dez. 2020. https://doi.org/10.22197/rbdpp.v6i3.374

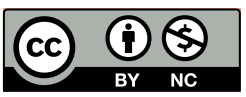

Esta obra está licenciada com uma Licença Creative Commons Atribuição-NãoComercial 4.0 Internacional. 